\title{
Democracia, Constituição e Relações Exteriores: o papel do Direito e da Cidadania no Contexto do Novo Constitucionalismo Latino-Americano
}

\author{
Democracy, Contitution and Foreign Relations: the role of Law and \\ Citizenship in the New Latin American Constitutionalism Context
}

\author{
Sergio Urquhart Cademartori \\ Centro Universitário La Salle, Canoas - RS, Brasil \\ José Alberto Antunes de Miranda \\ Centro Universitário La Salle, Canoas - RS, Brasil
}

Resumo: Estudos de Direito Constitucional apresentam o Constitucionalismo como um processo de evolução linear. Ora, nem sempre essa mesma evolução é encontrada nos países do terceiro mundo, como é o caso dos países da América Latina. A relação entre o Novo Constitucionalismo Latino-Americano e democracia surge no centro dos debates acadêmicos suscitando a questão central de saber até que ponto a soberania popular pode esgotar todo o seu exercício de legitimação do poder em um texto constitucional. Caso emblemático é o das normas explicitamente voltadas para orientar as relações externas do país que estabelecem princípios balizadores da ação do Estado, disciplinando os procedimentos e competências institucionais dos diferentes agentes, organismos e poderes públicos envolvidos na questão. Os Ministérios das Relações Exteriores permanecem refratários a essas influências, mas os movimentos sociais buscam alianças com setores do Estado que também querem mais espaço na agenda diplomática.

Palavras-chave: Constituição. Democracia. Relações Exteriores. Novo Constitucionalismo Latino-Americano.

Recebido em: 26/09/2015

Revisado em: 13/11/2015

Aprovado em: 09/03/2016
Abstract: The rules explicitly aimed to guide the external relations of a country established principles of the state action, regulating the procedures and institutional responsibilities of the different actors, organizations and public authorities involved in the issue. Constitutional Law studies have Constitutionalism as a linear evolution process, this same evolution is not always found in third world countries, as is the case of Latin America. The relationship between the New Latin American Constitutionalism and democracy appears in the center of academic debates raising the central question of the extent to which popular sovereignty may exhaust all his legitimacy power of exercise in a constitutional text. The formulation process of external relations has changed, with more and more groups within the Latin American society pushing for representation of their interests. The Ministries of Foreign Affairs remain refractory to these influences, but social movements seek alliances with state sectors that want more space on the diplomatic agenda.

Keywords: Constitution. Democracy. Foreign Affairs. New Latin American Constitutionalism. 


\section{Introdução}

A constituição deve ser considerada como uma norma não desvinculada da realidade e do meio social: na medida em que o direito é uma realização de fins considerados úteis e desejados como necessários, deve aquela partir da realidade empírica como pré-condição para atingimento de suas metas - este é o modo de funcionamento de uma constituição dirigente.

O propósito desse artigo é saber até que ponto a democracia e as normas constitucionais existentes representam efetivamente um conjunto significativo capaz de referenciar e organizar - internamente ao âmbito do Estado e da participação da sociedade - as ações voltadas para o desempenho das relações exteriores, no âmbito do chamado novo constitucionalismo latino-americano.

Como regra geral, tais relações são vistas fundamentalmente enquanto decorrência da política externa governamental e das influências que ela sofre dos diferentes segmentos da sociedade. Em função dessa perspectiva administrativista de tratamento da inserção do Estado na comunidade internacional, a política exterior tem manifestado, conceptual e historicamente, uma contumaz resistência à penetração, participação e o controle democráticos (DALLARI, 1994, p. 15).

O conjunto de relações externas de um país é determinado a partir de procedimentos complexos, que envolvem inúmeros parâmetros fixados por agentes distintos. Dessa forma, determinados organismos públicos, entidades privadas, organizações não governamentais, enfim uma quantidade grande de agentes, a partir de determinados critérios, valores, interesses e objetivos próprios, procura intervir no processo decisório acerca da inserção do país no quadro das relações internacionais.

Para este estudo, realizou-se revisão bibliográfica e análise documental de material disponibilizado nos sites governamentais de países que são representativos nos avanços da democracia e da participação cidadã e no que diz respeito ao papel do direito e da cidadania a partir do novo constitucionalismo latino-americano no campo da relação democracia, constituição e relações exteriores. 


\section{Democracia e Relações Exteriores}

As ações de relações externas de um país resultam de um somatório de variáveis econômicas e políticas e não de variáveis excludentes entre si, além da consideração das determinações estruturais e conjunturais. ${ }^{1}$

Isso nos leva a refletir sobre o estatuto teórico-político da política externa: constitui a mesma uma política de governo ou uma política de Estado? Em princípio, considera-se que a política externa represente os interesses nacionais (ou os interesses permanentes), realizando, portanto, uma política de Estado. Por isso, se diz que há nessa espécie de política uma relativa continuidade. Em relação aos governos, ressalva-se o surgimento de algumas mudanças de estilo ligadas à personalidade e ao estilo individual dos atores, bem como de adequação aos constrangimentos conjunturais.

A identificação mais acurada do processo de tomada de decisão em política externa mostra-se fundamental para a captação da complexidade das decisões tomadas, que são influenciadas por interesses estratégicos de inúmeros indivíduos e grupos afetados pela atuação internacional de seus Estados, tanto no executivo desses países como no legislativo e nos grupos de interesse. ${ }^{2}$ As decisões internacionais do Estado geram efeitos distributivos domésticos, podendo alterar o equilíbrio de forças interno e afetar a maximização de ganhos por tais indivíduos e grupos, como seu desempenho em processos eleitorais, por exemplo (HUDSON, 2005, p. 11-13).

Segundo Snyder, Bruck e Sapin (1962), na análise do processo decisório, o objeto de estudo deixa de ser o Estado, enquanto entidade abstrata, passando para a avaliação dos grupos ou seres humanos que tomam as decisões em nome do Estado. ${ }^{3}$

\footnotetext{
${ }^{1}$ A política externa é constituída por um conjunto de iniciativas que emanam do ator estatal, tendo em vista mobilizar para o serviço o máximo de fatores disponíveis tanto no ambiente interno como no ambiente externo (MERLE, 1992, p. 18).

${ }^{2}$ As ações de política externa não podem ser compreendidas sem a apreciação das suas fases de implementação as quais são tão importantes quanto o processo decisório, se observarmos que os resultados são com frequência diferentes das intenções originais (HILL, 2003, p. 51).

${ }^{3}$ A maior contribuição de Snyder, Bruck e Sapin (1962) para os estudos de política externa foi identificar o ponto de encontro teórico entre os determinantes mais importantes do
} 
O Estado corporifica-se assim nos agentes que tomam as decisões, o que leva às seguintes implicações:

a) a presunção de que a política internacional consiste em decisões adotadas por grupos ou pessoas e está formada de condutas que devem ser explicadas enquanto tais;

b) a definição da situação como uma função central dos que tomam as decisões e como um conceito-chave na análise da política exterior, imprimindo-lhe um elemento subjetivo muito diferente da suposta objetividade;

c) a descoberta de que existem fontes internas da política exterior de que esta é o resultado de um jogo em que intervêm diversas agências do Estado e numerosos grupos de interesse.

Os Estados não são atores unitários, ou seja, eles não são estritamente hierárquicos, mas são sim poliárquicos ${ }^{4}$, $\operatorname{compostos}$ por atores com diferentes preferências que compartilham poder em relação ao processo de tomada de decisão, mas grande parte das decisões não se relaciona diretamente em relação à sobrevivência do Estado (MILNER, 1997, p. 34).

$\mathrm{O}$ apoio de militares, da oligarquia, dos grandes negócios e dos partidos políticos é usualmente necessário, mesmo em governos autoritários que desejam permanecer no poder e implementar suas políticas. Esses grupos podem, eventualmente, exercer o poder de veto sobre as propostas do executivo, e, de outra maneira, definir a agenda, partilhando o poder com ele. Mesmo os líderes mais autocráticos dependem do suporte de grupos internos para reter suas posições e fazer política.

Os sistemas democráticos são ainda mais poliárquicos. Como os Estados não democráticos, eles variam em seus princípios de organização interna, alguns sendo mais anárquicos e outros mais hierárquicos. $\mathrm{Na}$ maioria dos casos, pelo menos, dois tipos de atores competem por contro-

comportamento do Estado: fatores materiais e ideológicos. O ponto de intersecção não é o Estado e, de acordo com os autores, é nesse ponto que as teorias clássicas e mesmo as contemporâneas necessitam de maior esclarecimento. O ponto de intersecção teórica é o tomador de decisão.

${ }^{4} \mathrm{Na}$ trilha da matriz categorial de Robert Dahl (2012, p. 352). 
le sobre o processo de tomada de decisão. Usualmente ambos, o legislativo e o executivo, influenciam na constituição da política.

A escolha de política externa a ser seguida é, portanto, o resultado do jogo estratégico entre atores domésticos na luta pelo poder interno. O interesse nacional depende das preferências e interesses da coalizão política vencedora e não apenas pode mudar, como também é objetivo de conflitos internos. A importância causal da política doméstica não é apenas o resultado de mudanças sistêmicas ou estruturais, mas depende da natureza da questão e da estrutura de preferências doméstica (MILNER, 1997, p. 36).

As relações internacionais são o conjunto de intercâmbio comercial, financeiro, cultural e institucional que se realiza além das fronteiras nacionais, hoje muito distintas das que eram a 20 ou 30 anos atrás. Entre outros fatores, os avanços na tecnologia, especialmente em matéria de transportes e comunicações tem eliminado muitos obstáculos que separam os países, conduzindo tanto no aumento do volume de transações internacionais como a uma mudança qualitativa em sua natureza (MINGST, 2009, p. 2-3).

O tratado de Westfália de 1648, que formalizou o fim da Guerra dos Trinta anos na Europa, representou a consolidação de uma ordem mundial constituída exclusivamente pelos governos de Estados soberanos. Estes teriam liberdade absoluta para governar um espaço nacional, territórios, podendo entrar em acordos voluntários e produzir tratados para regular as relações externas e intraconexões de vários tipos.

A noção de soberania, construída tendo como princípio, de um lado, a concepção de um poder originário, que não resulta de nenhum outro, do qual teria obtido o seu título; e de outro, a concepção de um poder supremo (superiorem non recognoscens), que não teria outro poder igual ou concorrente (MINGST, 2009, p. 23-26).

A paz de Westfália foi corroída por inúmeros fatores, dentre esses a tensão nunca superada entre a igualdade na teoria e a desigualdade de fato; a dificuldade de uma lógica coletiva, baseada apenas em uma ação descentralizada dos Estados, com um número muito grande de centros au- 
tônomos e semiautônomos de decisão; a internalização da economia e o liberalismo, que tornaram irreal a ideia de Estados autônomos e autossuficientes; e a disjunção verificada, no sistema internacional, entre ordem e poder, que fez que não vingassem ou não se perpetuassem, em diversos períodos da história, as tentativas de se suprir, a partir de um centro de gravidade política dotado de poder, as deficiências da lógica de Westfália na estabilização da ordem internacional.

Atualmente a corrosão dos paradigmas da Lógica de Westfália se aprofunda ainda mais, em razão de dois fenômenos que abalam o conceito tradicional de soberania; de um lado a necessidade e também os dilemas da cooperação intergovernamental, que decorre da diminuição do campo que anteriormente se incluía na esfera de jurisdição doméstica exclusiva do Estado, e se explica historicamente pela impossibilidade do Estado, no século XX, com as revoluções científicas e tecnológicas, de atender as suas necessidades numa base exclusivamente individual e territorial. De outro lado, o transnacionalismo, ou seja, aquelas relações que não transitam necessariamente pelos canais diplomáticos do Estado, mas que influenciam na sociedade e revelam que nenhum Estado é uma totalidade autossuficiente, pois classes, empresas, valores, e ideias, partidos, associações profissionais, grupos de pressão, são todos protagonistas no campo das relações externas, que agem por formas e caminhos próprios, agregando, por isso mesmo, uma significativa dimensão transnacional às relações internacionais (JACKSON; SORENSEN, 2007, p. 375-382).

Evidentemente no plano das relações externas, a pluralidade de tipos de pessoas ou sujeitos de direito foi sendo reconhecida até mesmo no campo mais específico do Direito Internacional Público.

Hoje em dia não se pode negar a personalidade internacional do indivíduo. Admiti-la é se enquadrar em uma das mais modernas tendências do direito Internacional Público, a democratização. É o homem pessoa internacional, como é o Estado, apenas a sua capacidade jurídica e de agir é bem mais limitada que a do Estado.

Esse crescente incremento do grau de complexidade do quadro de relações internacionais, com a multiplicação do número de protagonistas e procedimentos, faz aflorar a questão crucial da pluralidade de ordenamen- 
tos jurídicos, isto é, da impraticabilidade efetiva que se constata de se subordinar a um único sistema de normas toda a imensa gama de fatos jurídicos que se manifestam no plano internacional (DALLARI, 1994, p. 19).

No âmbito da normalização das relações internacionais, o pluralismo jurídico se manifesta na medida em que o direito internacional construído a partir da vontade dos Estados soberanos - e como projeção dos respectivos ordenamentos - convive com outros sistemas de regras, edificados com base na vontade de outros protagonistas que não os Estados.

$\mathrm{Na}$ medida em que, aparentemente, se verifica um movimento no sentido da acentuação do pluralismo de ordenamentos jurídicos na esfera internacional, com a consequente perda de peso relativo do sistema de normas fundado na vontade dos Estados soberanos, poder-se-ia questionar o porquê da preocupação atual com o tratamento de relações exteriores de um país no âmbito do ordenamento jurídico estatal.

Diversas razões provavelmente levaram a isso. A principal certamente decorre da circunstância de que não necessariamente se pode caracterizar como inevitável - e mesmo conveniente - a diluição do potencial normatizador do ordenamento estatal no tocante às relações internacionais (DALLARI, 1994, p. 27).

Observa-se que o conjunto de regras do ordenamento jurídico estatal, ao expressar e, simultaneamente, influenciar preocupações, ideias e valores, presentes na sociedade, interfere nos demais ordenamentos jurídicos lastreados nessa mesma sociedade e com eles interage.

Portanto, na medida em que os diferentes sistemas normativos não constituem compartimentos estanques e, muitas vezes, têm ideias e valores informadores comuns, o tratamento dado às relações exteriores do país no seio do ordenamento jurídico estatal não deixa de se configurar como fonte de referência em maior ou menor escala para os demais ordenamentos jurídicos.

Tradicionalmente a diplomacia na Idade Moderna era uma atividade sigilosa. Emanava do poder pessoal de soberanos absolutistas que não prestavam contas aos seus súditos de sua ação e da de seus agentes (MAQUIAVELO, 1987, p. 13; STOLLEIS, 1998, p. 23). Nesse contexto, o 
segredo era instrumento normal do exercício do poder (CADEMARTORI, S.; CADEMARTORI, D., 2011), pois os governantes adotavam como perspectiva, tida como legítima, a preocupação com a manutenção do seu poder e a necessidade de se defenderem de inimigos internos e externos (MAGALHÃES, 1995).

O sistema internacional contemporâneo tem, no entanto, como uma de suas características a heterogeneidade das formas de governo dos estados que o integram. Os Estados democráticos necessariamente atuam num contexto no qual nem todos são democráticos ou procedem de boa-fé. Daí, apesar da crescente publicidade da conduta externa dos estados, verifica-se a efetiva existência de limites ao ideal de diplomacia aberta. Por isso mesmo as democracias, quando atuam no campo diplomático, exercem o poder de maneira mais opaca. Isso se explica como a política externa enseja o sigilo (FIGUEIRA, 2011, p. 34).

$\mathrm{Na}$ democracia, por sua vez, duas razões são apresentadas para explicar a incidência de tal primazia, muito embora ela se dê em menor escala. Uma delas é o elevado grau de imprevisibilidade que marca a realidade de um sistema internacional acentuadamente heterogêneo e que induz o governo de cada Estado a adotar a opacidade - em relação a outros Estados, mas, por via de consequência, também em relação às demais instâncias do estado e aos próprios governados. A outra razão invocada diz respeito à noção das relações exteriores como um campo de conhecimento extremamente especializado, próprio da atuação de peritos, marcado por padrões de continuidade que não permitem as oscilações particulares às mudanças políticas internas a um Estado. ${ }^{5}$

\footnotetext{
${ }^{5}$ Quando se discute a gestão democrática das relações externas do Estado, faz-se referência a uma condução dos assuntos relativos à política exterior que se dê em conformidade com a orientação pretendida pela maioria dos membros do corpo político. Não há democracia concebível sem a participação, direta ou mediada por instituições, dos cidadãos nos assuntos relevantes à vida da polis. E, considerada a crescente relevância de questões internacionais, é razoável supor que a política externa integre o rol de políticas do Estado importantes para a autodeterminação de seu povo (LOPES, 2008, p. 100).
} 


\section{Constituição e Relações Exteriores}

As normas explicitamente voltadas para orientar as relações externas do país estabelecem princípios balizadores da ação do Estado, disciplinando os procedimentos e competências institucionais dos diferentes agentes, organismos e poderes públicos envolvidos na questão. Os atos de política externa são todos os atos de política interna que definem as modalidades de participação de um país no sistema de transferência internacional de recursos (bens, capital e tecnologia).

A análise dos princípios constitucionais que ditam parâmetros às relações exteriores de um país deve situá-los no quadro dos princípios políticos constitucionalmente conformadores. São princípios políticos constitucionalmente conformadores aqueles que explicitam as valorações políticas fundamentais do legislador constituinte (BARROSO, 2008, p. 155); a eles se somam, em um texto constitucional, os princípios jurídicos fundamentais, os princípios constitucionais impositivos e os princípios-garantia. Os princípios políticos constitucionais manifestam-se como princípios constitucionais fundamentais, positivados em normas-princípio, e se distinguem dos princípios jurídicos constitucionais, que são informadores da ordem jurídica nacional e, não raro, constituem desdobramentos ou princípios derivados) dos fundamentais (CUNHA, 2006, p. 34).

A compreensão de uma lei constitucional só ganha sentido útil, teórico e prático, quando referida a uma situação constitucional concreta, historicamente existente num determinado país. Essa regra se aplica inclusive para a apreciação das normas constitucionais voltadas para o plano das relações exteriores, já que se torna extremamente relevante, para sua interpretação e para o dimensionamento de sua repercussão, a análise do quadro de relações estabelecido na ordem internacional e a avaliação da presença do país no âmbito desse quadro (BONAVIDES, 2008, p. 45).

No caso do Brasil o arrolamento efetuado no artigo $4^{\circ}$ da Constituição de 1988 representa, em relação aos textos constitucionais anteriores, uma inovação importante na sistematização de paradigmas que devem reger as relações exteriores do Brasil. 
Por outro lado, os princípios previstos na constituição brasileira não podem ser vistos meramente como figuras retóricas, até porque repercutem em diversos dispositivos constitucionais não só localizadores da presença brasileira na comunidade internacional, mas, inclusive, disciplinadores de direito inerentes à ordem jurídica interna (POLVEIRO JUNIOR, 2008, p. 45).

Exemplo dessa repercussão decorre da explicitação do princípio da cooperação entre os povos para o progresso da humanidade se coadunar com a indução à formação de uma comunidade latino-americana de nações, base constitucional para o engajamento efetivo do Brasil no processo de institucionalização do Mercosul e da Unasul (CADEMARTORI, D. et al., 2012). Vários outros países latino-americanos fazem essa menção em suas constituições como Argentina, Uruguai e Paraguai.

É importante se analisar o debate em torno da identificação da perspectiva geral orientadora das diretrizes constitucionais fixadas para as relações exteriores dos países latino-americanos. Existe uma orientação nacionalista que se apega as ideias de independência nacional, de não intervenção, da igualdade entre os estados. Por outro lado, há uma linha internacionalista que se traduz na ideia de que as relações internacionais de alguns países deverão valer-se pela prevalência dos direitos humanos da autodeterminação dos povos e do repúdio ao terrorismo e ao racismo.

Estudos de Direito Constitucional apresentam o Constitucionalismo como um processo de evolução linear, mas nem sempre essa mesma evolução é encontrada nos países do terceiro mundo, como é o caso dos países da América Latina. A relação entre o Novo Constitucionalismo Latino-Americano e democracia surge no centro dos debates acadêmicos suscitando a questão central de se saber até que ponto a soberania popular pode esgotar todo o seu exercício de legitimação do poder em um texto constitucional.

Os países no sistema internacional desenvolvem intensas relações externas em diferentes âmbitos. Alguns países promoveram ou estão promovendo alterações em seus dispositivos constitucionais. O novo constitucionalismo que surge em alguns países, principalmente na América Latina traz consigo o conceito de democracia consensual e não hegemônica. 
Essa democracia consensual tem ou não se refletido no âmbito das relações externas desses países.

A adoção, nas novas constituições latino-americanas, de instrumentos oriundos da democracia direta e da democracia participativa revela a vontade que o povo tem de mudar as estruturas políticas e jurídicas de Estado a seu favor, passando a assumir o papel de protagonista na história de seus respectivos países (TAVARES; FREITAS, 2013, p. 35).

A redemocratização dos países latino-americanos teve importante impacto na política externa de alguns desses países, aproximando as políticas sociais da agenda de cooperação internacional. Temas como segurança alimentar e saúde pública são um exemplo. Contudo, persistem resistências nos Ministérios das Relações Exteriores em grande parte dos países latino-americanos com respeito à participação cidadã na diplomacia. Decisões relativas à promoção e defesa da democracia têm sido contraditórias e instáveis. Observa-se maior presença dos movimentos sociais em redes transnacionais em toda a América Latina, o que determinou alterações na luta política em áreas como meio ambiente e direitos humanos, com grupos locais buscando aliados no exterior para compensar sua fragilidade doméstica.

À medida que a sociedade civil no continente latino americano desenvolve-se e amadurece, aumenta sua presença em redes transnacionais; as fronteiras entre política doméstica e externa tornam-se mais tênues e configuram-se novas alianças entre atores nacionais e parceiros estrangeiros, aumentando a pressão sobre os governos na formulação da agenda diplomática.

No Brasil, por exemplo, a democracia também inovou ao criar conselhos de políticas públicas, nos âmbitos federal, estadual e municipal, que reúnem representantes da sociedade civil e integrantes dos diversos níveis do governo brasileiro. Em geral de caráter consultivo, funcionam como fóruns de debate, fiscalização e prestação de contas. Nasceram na área social, abarcando temas como saúde, assistência social, educação, e proteção de crianças e adolescentes. Expandiram-se para mais de 30 mil, abarcando também campos como segurança pública e desenvolvimento socioeconômico. A política monetária e a diplomacia são as exclusões 
mais significativas dessa onda de participação cidadã̃ nos assuntos públicos (DAGNINO; OLIVERA; PANFICHI, 2006, p. 56; IBASE, 2014, p. 4). ${ }^{6}$

A ausência ou baixa participação do legislativo em prol do executivo em decisões de política externa não é o ideal. É importante haver um maior equilíbrio decisório entre os dois poderes. A abdicação pode acarretar grandes defeitos, segundo Lima e Santos (2001, p. 56-59), como:

a) uma política distante do ponto ideal para o legislador mediano;

b) instabilidade decisória, tendo em vista os conflitos e pressões interburocráticas;

c) o favorecimento de alguns grupos, escapando à representatividade e ao controle da sociedade.

$\mathrm{Na}$ linha de análise de Maria Regina Soares de Lima, a virtude do institucionalismo em particular a divisão de poderes e a existência de checks and balances são mais efetivas nas democracias. Tais mecanismos restringem a liberdade total dos decisores governamentais que, de outro modo, poderiam declarar guerra pelos motivos mais triviais. Os estudos que trazem a representação do Estado como ator coeso e autônomo constitui, segundo a autora, uma excessiva simplificação na representação de um ator complexo como é o Estado. A autora ainda realça o que aconteceu no século XVII com a destruição do frágil constitucionalismo existente quando pôs em marcha o absolutismo burocrático-militar. Na época, a ameaça, do Estado prussiano de uma invasão externa fez substituir uma tradição já centenária de processualismo pela Raison d'État.

\footnotetext{
${ }^{6}$ Um importante exemplo é a política pública brasileira de combate à AIDS é fruto do novo ambiente democrático, com a intensa interlocução entre movimentos sociais e o Ministério da Saúde, chamando atenção para os impactos da doença e para a necessidade de o Estado custear o tratamento de custo elevado. Ao longo dos anos, isso levou à consolidação do uso de medicamentos genéricos nos coquetéis de remédios contra o vírus HIV. Na Organização Mundial do Comércio, o Brasil defendeu o licenciamento compulsório desses produtos, em conflito com os interesses das grandes empresas farmacêuticas. O resultado do embate foi favorável às pressões brasileiras e de outras nações em desenvolvimento, como Índia e África do Sul, com a elaboração da Declaração de Saúde Pública da OMC (2001), vinculada aos acordos TRIPS, sobre patentes e propriedade intelectual (SANTORO, 2012).
} 
As instituições políticas que se caracterizam por menor concentração de poder decisório, como é o caso do sistema presidencialista de governo, cuja base é a separação de poderes, multiplicariam os pontos de veto e a incerteza com respeito à ratificação doméstica de acordos internacionais. Segundo a autora, o ressurgimento da perspectiva institucionalista na análise política, focalizando a dinâmica institucional do processo de decisão e o exame dos fatores que facilitam ou não os governos na implementação de seus programas legislativos, direcionou a análise para os pontos de veto em processos decisórios como um dos principais fatores institucionais responsáveis pela definição dos resultados políticos. Naturalmente que quanto mais concentrado o processo decisório, menos pontos de veto existirão e maior a facilidade de o executivo implementar políticas de sua preferência (LIMA, 2000, p. 271 -281).

Em política externa, a questão do accountability foi amplamente discutida desde a Primeira Guerra Mundial. Por outro lado, poucos países possuem de forma clara mecanismos estabelecidos, e mesmo quando o têm, a prática não corresponde à teoria. Na verdade, pode-se argumentar que condições para o accountability, frequentemente, tem sido, de forma deliberada, sacrificadas sobre o suposto interesse primordial na segurança e em um executivo efetivo.

Vistos esses aspectos gerais, cabe agora examinar o chamado Novo Constitucionalismo Latino-americano e a democratização da formulação de políticas públicas dentro do âmbito da política externa. Tal se fará a partir de uma breve análise das características das novas Cartas, desembocando na constatação da existência ou não do protagonismo da cidadania nesse campo.

\section{O Novo Constitucionalismo Latino-Americano}

A análise das Cartas Magnas no âmbito de algumas nações latino-americanas e o impacto que elas apresentam ante as ações de política externa desses países permitem afirmar que vivemos em um período importante na defesa das garantias e liberdades democráticas. 
No recente constitucionalismo latino-americano a necessidade de avanços político-constitucionais e de mudanças sociais profundas fez com que alguns países da região passassem a reconhecer a necessidade de reformular o seu projeto político-democrático. Nesse sentido, buscam torná-lo mais eficaz, em particular no resgate da proximidade dos seus cidadãos ao poder político governamental, e no reconhecimento das suas múltiplas condições existenciais e sociais, e, ainda na sua transformação em direitos inseridos nas novas constituições, os quais repercutiram em um processo conhecido como o Novo Constitucionalismo na América Latina. ${ }^{7}$

O Novo Constitucionalismo busca analisar, no primeiro momento, a fundamentação da Constituição, sua legitimidade, que por sua própria natureza, só pode ser extrajurídica e, posteriormente, como consequência daquela, interessa a efetividade da Constituição, com particular referência - neste ponto conectado com os postulados neoconstitucionalistas - a sua normatividade (PASTOR; DALMAU, 2011, p. 34).

O Novo Constitucionalismo constitui-se em uma teoria de avanço democrático da Constituição, por força do qual o conteúdo desta deve expressar, nos limites de suas possibilidades, a vontade soberana de seu povo, o reconhecimento de sua identidade, de sua consciência cultural, dos valores que almejam preservar, e da sua melhor forma de organização social e política, cuja prática deverá ser alcançada por meio de mecanismos de participação popular direta, da garantia dos direitos fundamentais, do procedimento de controle de constitucionalidade promovido pelos cidadãos e da criação de regras que limitem os poderes políticos, econômicos, sociais e culturais.

O Novo Constitucionalismo latino-americano vem ao encontro de lutas e de reivindicação popular por um novo modelo de organização do Estado e do Direito que, além de reconhecer, legitimar e ampliar o rol dos

\footnotetext{
7 O Novo Constitucionalismo latino-americano surgiu com a intenção de legitimar e de expandir a democracia dentro dos países da América Latina e de efetivar os direitos estabelecidos nos seus textos constitucionais. Esse movimento iniciou-se com a Constituição da Colômbia de 1991, logo após, em 1999, atingiu a Constituição da Venezuela e alcançou o seu ápice com as constituições do Equador (2008) e da Bolívia (2009) (PASTOR; DALMAU, 2010a).
} 
direitos fundamentais possa também efetivá-los no caso concreto. A partir desse modelo se exige um governo em que sua constituição se legitime no ideal de democracia e na identidade do povo e não necessariamente em padrões externos ocidentais que não guardam correspondência com a cultura genuinamente latino-americana. $\mathrm{O}$ modelo pode ser compreendido como uma bússola que aproxima mais o povo do poder político democrático na busca e na construção do seu bem-viver (CADEMARTORI, D.; CADEMARTORI, S., 2014, p. 8 e 18).

Esse novo tipo de democracia promoveria a participação direta do povo na elaboração e aprovação da constituição, como também do controle dos poderes estatais e as decisões tomadas pelos representantes políticos. As atuais constituições latino-americanas que apresentam essas características baseiam-se fundamentalmente em princípios jus-positivistas e em mecanismos e procedimentos da democracia participativa, o que significa um maior detalhamento acerca dos conceitos e do campo de aplicação dos já mencionados princípios constitucionais, bem como na participação dos povos, nas decisões governamentais que, muitas vezes, podem determinar seus destinos. ${ }^{8}$

$\mathrm{Na}$ constituição de algum desses países que adotaram o modelo do Novo Constitucionalismo houve significativas mudanças de avanço democrático, com adoção de formas de democracia direta para legitimar seus governantes, e exatamente, em decorrência da ampliação desta participação popular, detectam-se câmbios substancialmente ainda mais profundos, mediante a institucionalização da proposta do Bem-viver, na vanguarda do giro ecocêntrico, superador do modelo antropocêntrico que alicerça os atuais sistemas jurídicos (WOLKMER, 2012, p. 16).

\footnotetext{
${ }^{8}$ Emerge dos cenários, social, político e jurídico, na região dos Andes na América Latina, um constitucionalismo de feição ecocêntrica, o qual ostenta como bandeiras o reconhecimento dos direitos da natureza (Pachamama) e a cultura o Bem viver, tendo com principais centros irradiadores de mudanças, o Equador e a Bolívia, cujas reformas constitucionais recentes, respectivamente, em 2008 e 2009, a partir da inclusão dos povos indígenas e de outras minorias étnico-raciais, como atores sociais na atualidade, incorporaram vetustos valores resgatados das raízes pré-colombianas comuns, entre os quais se sobressai o respeito à natureza e ao ambiente (FREITAS; MORAES, 2013, p. 15).
} 
Assim sendo, cabe agora examinar as características das Constituições que propiciaram que se possa falar de um "Novo" constitucionalismo no subcontinente.

\section{Características das Novas Constituições Latino-Americanas}

Viciano Pastor e Martínez Dalmau (2010a, p. 22) arrolam as características das novas Cartas da América Latina de forma bastante exaustiva, pelo que aqui se segue a orientação imprimida pelos autores meniconados na análise desses fenômenos.

Quanto às condições factuais, entendem os autores valencianos que as novas Constituições desfrutam de vasta legitimidade, pois respondem a uma proposta social e política, sendo precedidas por mobilizações que evidenciaram a sua necessidade e, conforme o caso, foram antecedidas e sucedidas por referendos ativador e ratificador.

$\mathrm{Na}$ análise dos autores, a legitimidade é percebida como adequação normativa da resposta a uma situação de fato, pelo que deixa de abranger seu aspecto propriamente axiológico: a correspondência das normas constitucionais aos valores veiculados pelas Cartas de direitos fundamentais ${ }^{9}$.

Inobstante isso, as Cartas em análise apresentam alto grau de legitimidade, dada a sua estreita vinculação aos catálogos de direitos incorporados por elas, como adiante se verá.

\subsection{Características Formais}

Pastor e Dalmau enumeram as características formais das leis fundamentais do subcontinente, cujo exame permite concluir que elas preenchem as condições de constitucionalização (GUASTINI, 2009, p. 50) haja vista a sua estrutura e os mecanismos por elas previstos e a seguir relacionados.

Mas, especificamente, são características formais das novas Cartas:

${ }_{9}^{9}$ Sobre o tema cfr. Cademartori (2007). 
a) Conteúdo Inovador (originalidade): no que diz com o conteúdo das Cartas, os autores valencianos salientam o seu caráter inovador, eis que aquelas veiculam institutos de todo originais: em primeiro lugar, enfatizam a criação do referendo revogatório dos mandatos políticos ${ }^{10}$, instrumento de participação popular e democracia direta de inegável valor para a manutenção da soberania popular.

Ainda nessa seara do controle e fiscalização do Poder, festejam como um dos mecanismos importantes para a previsão, pela Constituição do Equador, do Conselho de Participação cidadã e controle social. ${ }^{11}$

Apontam ainda para a nova divisão de poderes prevista na Constituição da República Bolivariana da Venezuela: para enfatizar o poder popular, é previsto o Poder Cidadão, além do Poder Eleitoral, este último, entendido aqui como despiciendo, já que a solução brasileira, da criação da Justiça Eleitoral como um braço do Judiciário parece funcionar a contento. ${ }^{12}$

Por último, o princípio da plurinacionalidade, que estrutura a nova ordem jurídico-política, tanto da Bolívia quanto do Equador, eis que presente nas respectivas Cartas.

b) Extensão: as novas Constituições latino-americanas são extensas e acentuadamente analíticas, o que leva Viciano e Martínez a salientar o estreito vínculo dos poderes constituídos com a soberania popular representada pelo Poder Constituinte. Deve-se alertar, no amarrar as gerações futuras nos mais comezinhos detalhes, os valores da geração que elaborou a Carta.

c) Tratamento da complexidade com linguagem acessível: o próprio fato da analiticidade das Constituições estrutura um ordenamento bastante complexo, fruto, outrossim, da complexidade das relações sociais nas sociedades contemporâneas. Citam os pro-

\footnotetext{
10 Constituição da Bolívia, Artigo 240, I; Constituição da Colômbia, Artigo 103; Constituição do Equador, Artigo 145; Constituição da Venezuela: Artigo 70.

${ }^{11}$ Artigos 207 e 208

${ }^{12}$ Artigo 136
} 
fessores valencianos um exemplo extraído da Carta da Venezuela, que determina a coordenação de políticas físcais e monetárias através de acordo de políticas macroeconômicas, bem como os processos de eleição para membros do $\mathrm{CNJ}$ e TC na Bolívia.

De outro lado, denotam-se as preocupações dos constituintes em estabelecer uma linguagem acessível aos cidadãos, numa relação de comunicação/educação política importante: veja-se o caso do artigo $8^{\circ}$ da Constituição da Bolívia. ${ }^{13}$

d) Alteração constitucional através da ativação do poder Constituinte popular

A última característica formal apontada pelos professores de Valencia (PASTOR; DALMAU, 2010, p. 32-34) leva à conclusão de que eles entendem que as novas Constituições preveem sua alteração exclusivamente através do poder Constituinte, o que não é verdade. Com efeito, dizem os autores que "[...] as constituições venezuelana de 1999 e boliviana de 2009 marginalizaram completamente o poder constituído"14. Pela leitura que se faz das referidas Cartas, não corresponde à realidade essa assertiva. $^{15}$

e) características materiais: Viciano Pastor e Martínez Dalmau (2010) iniciam a análise dos elementos materiais inovadores das recentes constituições latino-americanas por um elemento que não é material, mas sim formal: as novas formas de participação vinculante, como são aquelas - das quais algumas foram já mencionadas acima - que dizem respeito à participação direta do povo e exercício da democracia direta pela cidadania. Com efeito, esses mecanismos de manifestação do poder político dizem respeito a quem decide e como decide politicamente (elementos

\footnotetext{
${ }^{13}$ Artigo 8. I

14 "[...] las constituciones venezolana de 1999 y boliviana de 2009 han marginado completamente al poder constituido." (PASTOR; DALMAU 2010, nota 26, p. 33)

15 Constituição da Bolívia, Artigo 411; Constituição do Equador: Artigos 441 e 442; Constituição da Venezuela: Artigos 342, 343, 344 e 345; Constituição da Colômbia: artigos 374 e 377.
} 
formais) e não sobre o que se pode decidir ou sobre o que não se pode deixar de decidir (no primeiro caso, liberdades e no segundo, direitos sociais). É que, como diz Ferrajoli (1995, p. 864866), a democracia apresenta duas facetas: a formal, constituída pelas condições formais de validade das decisões (que determina competências e procedimentos, ou seja, os referidos quem decide e como decide) e a substancial (que condiciona as mesmas decisões a conteúdos jurídicos - os direitos fundamentais - que devem ser veiculados por aquelas).

De outro lado, deve-se ter sempre presente um risco para a democracia: o apelo ao povo que sustenta teoricamente o novo constitucionalismo apresenta aspectos problemáticos. Se por um lado é feito um forte apelo democrático, corre-se sempre o risco de que, pela adoção desse mecanismo, se acabe por aniquilar a democracia. Repisando: se à vontade popular (soberania popular) é deferida a possibilidade de alteração da Constituição sem limites, pode-se acabar repetindo as experiências fascista e/ou nazista, ou seja, a entrega formalmente democrática (ou seja, majoritária) do poder a quem vai aniquilar a democracia. Nesse sentido, o aspecto de direito do Estado não deve ser descurado em favor da democracia procedimental. Com efeito, a própria noção de soberania popular pode ser questionada, já que na realidade não se pode obter de uma sociedade complexa e cindida em classes, uma vontade única. A metáfora de Ulisses relacionada às sereias deve estar sempre presente.

De qualquer sorte, esse elemento formal de democratização do poder se encontra presente nas Cartas ora em análise, em sedes tais como no controle concentrado de constitucionalidade, tendo como exemplo a eleição direta de magistrados para o Tribunal Constitucional na Bolívia ${ }^{16}$, não sendo em absoluto desprezível o seu exercício para promoção da dignidade humana.

O principal elemento material de inovação aparece nas Cartas de direitos incorporadas a essas Constituições, catálogos que atentam para as especificidades dos grupos sociais (mulheres, crianças, velhos etc.) e suas necessidades diferenciadas. Assim, encontram-se direitos e garantias em

${ }^{16}$ Artigo 198 da Constituição da Bolívia 
profusão, dirigidos a esses grupos, constituindo-se em leis do mais fraco (FERRAJOLI, 1999, p. 37-73).

Outro aspecto material, ao passo que formal, importante, é a recepção de convênios internacionais de direitos humanos por essas Cartas: por exemplo, por força da Constituição do Equador, se o tratado incorpora norma mais favorável aos direitos humanos do que a Constituição, aquele prevalece. Outrossim, na Venezuela, os tratados de direitos tem estatura constitucional, prevalecendo também a norma mais benéfica.

De outra parte, aplicam-se na interpretação das normas os critérios mais favoráveis aos direitos fundamentais, com o fito de conferir máxima efetividade para os direitos sociais.

Por último, lembram Viciano Pastor e Martínez Dalmau (2010) que essas Cartas são verdadeiras Constituições econômicas, com detalhamento do planejamento dessa área e forte presença do Estado na economia.

\section{O Papel do Direito e da Cidadania ante as Relacões Externas no Novo Constitucionalismo Latino-Americano}

Política e Direito têm sido há muito tempo vistos como um domínio em separado das relações internacionais, como esferas de ação com suas próprias e distintas lógicas e consequências. Essa visão é tão forte que as disciplinas de relações internacionais e direito têm se desenvolvido em paralelo, sem questionar seus campos em comum, estando cada uma com suas próprias distinções e autonomia ${ }^{17}$ (REUS-SMIT, 2004, p. 1-13).

Os teóricos do direito, frequentemente, reivindicam a manutenção da diferenciação do direito em relação à política por medo de que a intrusão desta iria minar o caráter distintivo da lei como um sistema de regras imparciais. Em consequência, política internacional e direito têm

\footnotetext{
${ }^{17}$ É curioso que muitos dos estudiosos do direito internacional aceitaram essa separação. Com algumas exceções, o direito internacional tem sido apresentado como um regime regulatório, externo ao corte e impulso da política internacional, uma constituição de regras e de práticas institucionais fixadas no sentido de limitar e moderar a ação política (KOSKENNIEMI, 2000, p. 17-34).
} 
sido tratados como categorias distintas e enquanto o direito internacional tem tido pouco espaço nos currículos de relações internacionais, os estudantes de direito tem apreendido doutrina e processo, mas não política (KOSKENNIEMI, 2000, passim).

Hoje o discurso político está permeado pela linguagem do direito e da legitimidade, dado que elas, tanto quanto a "realpolitik", são centrais às campanhas militares como estratégicas. Os direitos possuem tanto recurso de poder quanto armas e dinheiro. Assim como a soberania jurídica motivou as normas legais da sociedade internacional, eles estão tornando-se a chave determinante do poder do Estado.

Se a política externa é considerada como uma entre as várias políticas públicas de um Estado democrático (LAFER, 2001, p. 23; LIMA, 2000, p. 54), é relevante entender como se processa, teórica e empiricamente, esse (aparente) contrassenso: não deveriam as relações externas de um Estado estar efetivamente submetidas ao controle democrático da população - como em princípio ocorre ou deveria ocorrer com as demais políticas públicas?

A elaboração da política exterior sempre foi entendida como um assunto que diz respeito ao alto escalão governamental e não ao cidadão comum, pois se considera que o cidadão não teria exata noção do que significariam as ações internacionais ${ }^{18}$ (POLVEIRO JUNIOR, 2008, p. 34).

Se no constitucionalismo clássico o enfoque das relações exteriores se restringiu praticamente à fixação de competências entre os diferentes poderes, esferas e organismos do Estado, a constitucionalização de princípios de relações exteriores tem sido uma marca dos textos mais recentes, como é possível constatar pela leitura das Cartas produzidas a partir dos processos de democratização ocorridos na América Latina. A constitucionalização dos princípios de relações exteriores viabiliza o controle políti-

${ }^{18} \mathrm{O}$ conceito de cidadania engloba necessariamente o enfrentamento da complexidade dos conflitos por direitos advindos de uma sociedade fragmentada pela multiplicação das desigualdades sociais. A condição essencial para a prática da cidadania é a explicação dos conflitos, e sua mediação pela sociedade política. Cidadania se adquire por cooperação, negociação, convergência de interesses e tentativa de apaziguamento desses conflitos inerentes a sociedade contemporânea (DUPAS 2005). 
co da ação externa do Estado pelo Poder Legislativo e o controle jurídico pelo Poder Judiciário (DALLARI, 1994, p. 67).

No entanto, pelo que se depreende da leitura das constituições mais representativas do Novo Constitucionalismo Latino-americano (entendidas estas aqui como as da Colômbia, Venezuela, Equador e Bolívia) ainda é um tema ignorado (ou negado) o da formulação de políticas em termos de relações internacionais.

Com efeito, a Constituição da Colômbia, ao abordar as Relações Internacionais (artigos 224 a 227), mantém os mecanismos tradicionais de formulação de estratégias externas.

Já as Cartas da Venezuela, Equador e Bolívia abrem espaço para a participação popular através de mecanismo de democracia direta (referendo e plebiscito) apenas no que tange aos tratados e acordos internacionais, passo necessário, mas de todo insuficiente para garantir a presença cidadã de forma imediata na elaboração das estratégias de política exterior.

Assim, estabelece a Carta da República Bolivariana da Venezuela:

Artículo 73. [...] Los tratados, convenios o acuerdos internacionales que pudieren comprometer la soberanía nacional o transferir competencias a órganos supranacionales, podrán ser sometidos a referendo por iniciativa del Presidente o Presidenta de la República en Consejo de Ministros; por el voto de las dos terceras partes los y las integrantes de la Asamblea o por el quince por ciento de los electores y electoras inscritos en el registro civil y electoral.

Na mesma lógica, a Constituição da Bolívia reserva a participação da nação apenas ao campo dos tratados:

Artículo 257.

Los tratados internacionales ratificados forman parte del ordenamiento jurídico interno con rango de ley.

II. Requerirán de aprobación mediante referendo popular vinculante previo a la ratificación los tratados internacionales que impliquen: 
Cuestiones limítrofes.

Integración monetaria.

Integración económica estructural.

Cesión de competencias institucionales a organismos internacionales o supranacionales, en el marco de procesos de integración.

Artículo 258.

Los procedimientos de celebración de tratados internacionales se regularán por la ley.

Artículo 259.

Cualquier tratado internacional requerirá de aprobación mediante referendo popular cuando así lo solicite el cinco por ciento de los ciudadanos registrados en el padrón electoral, o el treinta y cinco por ciento de los representantes de la Asamblea Legislativa Plurinacional. Estas iniciativas podrán utilizarse también para solicitar al Órgano Ejecutivo la suscripción de un tratado.

De seu lado, dispõe a Constituição do Equador: “Art. 420. La ratificación de tratados se podrá solicitar por referéndum, por iniciativa ciudadana o por la Presidenta o Presidente de la República”.

Ressalte-se que a Carta equatoriana consagra e promove a ampla participação popular em todos os níveis internos ao Estado, dedicando um capítulo inteiro (capítulo primeiro do título IV: "Participación y organización del poder") aos mecanismos de participação direta da cidadania na gestão pública. De fato, o artigo 100 da Carta detalha os âmbitos em que a participação do povo é reclamada:

Art. 100 En todos los niveles de gobierno se conformarán instancias de participación integradas por autoridades electas, representantes del régimen dependiente y representantes de la sociedad del ámbito territorial de cada nivel de gobierno, que funcionarán regidas por principios democráticos. La participación en estas instancias se ejerce para:

1. Elaborar planes y políticas nacionales, locales y sectoriales entre los gobiernos y la ciudadanía. 
2. Mejorar la calidad de la inversión pública y definir agendas de desarrollo.

3. Elaborar presupuestos participativos de los gobiernos.

4. Fortalecer la democracia con mecanismos permanentes de transparencia, rendición de cuentas y control social.

5. Promover la formación ciudadana e impulsar procesos de comunicación. Para el ejercicio de esta participación se organizarán audiencias públicas, veedurías, asambleas, cabildos populares, consejos consultivos, observatorios y las demás instancias que promueva la ciudadanía.

Como se pode ver, a área das relações externas é a grande ausente deste rol de temas. Assim sendo, tudo leva a crer que, embora essas Constituições hajam implementado e desenvolvido fortemente a participação cidadã nos assuntos públicos, o cerne das políticas de soberania mantém-se intocado pelo grande público, continuando a ser "arcana imperii", como em toda a tradição ocidental.

\section{Conclusão}

À medida em que a América Latina torna-se mais democrática, sua sociedade civil organiza-se melhor e reforça seus vínculos transnacionais, inclusive com movimentos sociais em países autoritários ou de democracia frágil. Esses laços criam grupos de pressão sobre a implementação das relações externas de um país, criando para o governo ambiente mais conflituoso, de maior escrutínio sobre suas ações.

As relações entre democracia e a constituição tem consequências importantes para as relações externas dos países. Grande parte dos países latino-americanos promoveram mudanças de regime, o que significou transformações no direcionamento das relações externas desses países, com uma agenda de cooperação internacional enriquecida pelas novas políticas sociais e por ações mais assertivas (ainda que ambíguas e contraditórias) na defesa das liberdades democráticas, sobretudo na América Latina. 
O processo de formulação das relações externas foi alterado, com cada vez mais grupos dentro da sociedade latino-americana pressionando pela representação de seus interesses. Os Ministérios das Relações Exteriores permanecem refratários a essas influências, mas os movimentos sociais buscam alianças com setores do Estado que também querem mais espaço na agenda diplomática.

A democracia é um processo em permanente construção. A jovem democracia latino-americana já apresenta em alguns países um longo período de liberdades civis e políticas, mas há ainda um longo caminho a percorrer. Dentro dessa tendência, o Novo Constitucionalismo Latino Americano trouxe um viés mais pluralista e inclusivo na lógica política, mas ainda não há indícios claros de que o direito e os cidadãos exercem maior influencia na relação entre democracia, constituição e relações exteriores, último bastião inexpugnável da absolutista Razão de Estado.

\section{Referências}

ACKERMAN, B. A nova separação dos poderes. Rio de Janeiro: Lumen Juris, 2007.

ALMEIDA, P. R. Relações exteriores e constituição. Revista Brasileira Política Internacional, Brasília, DF, v. 29, n. 115, p. 83-90, 1986.

ALMEIDA, P. R. A Estrutura Constitucional das Relações Internacionais e o Sistema Político Brasileiro. Revista Contexto Internacional, Rio de Janeiro, v. 12, n. 6, p. 53-69, jul.-dez. 1990.

AYERBE, L. F. (Org.). Novas lideranças políticas e alternativas de governo na América do Sul. São Paulo: Ed. Unesp, 2008.

BARROSO, L. R. Interpretação e aplicação da constituição. São Paulo: Saraiva, 2008.

BOBBIO, N.; MATTEUCCI, N.; PASQUINO, G. Dicionário de política. Brasília, DF: Editora UNB, 2010. 
BONAVIDES, P. Teoria constitucional democrática participativa. São Paulo: Malheiros, 1997.

BONAVIDES, P. Política e direito. São Paulo: Malheiros, 2008.

CADEMARTORI, D.; CADEMARTORI, S. Apontamentos para uma concepção marxista de desenvolvimento e a alternativa do "vivir bien/ buen vivir". In: BELLO, E. (Org.) Direito e marxismo: transformações na América Latina contemporânea. Caxias do Sul: Educas, 2014. v. 3. p. 47-62.

CADEMARTORI, D. et al. (Org.). A construção jurídica da Unasul. Florianópolis: EdUFSC, 2012.

CADEMARTORI, S. Estado de direito e legitimidade: uma abordagem garantista. 2. ed. Campinas: Millenium, 2007.

CADEMARTORI, S. U.; CADEMARTORI, D. O poder dos segredos e os segredos do poder: uma análise histórico-conceitual dos limites e possibilidades de convivência entre o segredo e a democracia. Novos Estudos Jurídicos, Itajaí, v. 16, n.3, p. 329-344, 2011.

CAVAROZZI, M. Ação presidencial na América Latina: antecedentes históricos e uma tipologia do século XXI. In: FAUSTO, Sergio (Org.). Difícil Democracia, São Paulo: Paz e Terra. p. 16-51, 2010.

CERVO, L. A. Relações internacionais da América Latina: velhos e novos paradigmas. São Paulo: Saraiva, 2007.

COUTO, E. F. Judicialização da Política Externa e Direitos Humanos. Revista brasileira política internacional, Brasília, v. 47, n. 1, jun. 2004. Disponível em: <http://www.scielo.br/ scielo.php?script=sci_ arttext\&pid=S0034-73292004000100007\&lng=en\&nrm=iso $>$. Acesso: em: 8 abr. 2014.

CUNHA, S. Princípios constitucionais. São Paulo: Saraiva, 2006. DAGNINO, E; OLIVERA, A.; PANFICHI, A. (Org.). A disputa pela construção democrática na América Latina. Rio de Janeiro: Paz e Terra, 2006. 
DAHL, R. Poliarquia, participação e oposição. São Paulo: EDUSP, 1997.

DAHL, R. A democracia e seus críticos. São Paulo: Martins Fontes, 2012.

DALLARI, P. Constituição e relações exteriores. São Paulo: Saraiva, 1994.

DUPAS, G. Atores e Poderes na nova ordem global: assimetrias, instabilidades e imperativos de legitimação. São Paulo: Unesp, 2005.

FERRAJOLI, L. Derecho y Razón: teoría del garantismo penal. Madrid: Trotta, 1995.

FERRAJOLI, L. Derechos y garantías. La ley del más débil. Madrid: Trotta, 1999.

FIGUEIRA, A. Introdução a analise de política externa. São Paulo: Saraiva, 2011.

FREITAS, R.; MORAES, G. O novo constitucionalismo americano e o giro ecocêntrico dos Andes: os direitos de Pachamama e o bem-viver na constituição do Equador e da Bolívia. In: FREITAS, R.; MORAES, G. Unasul e o novo constitucionalismo Latino-Americano. Curitiba: CRV, 2013. p. 32-73.

GOLDSTEIN, J.; KEOHANE, R. Ideas and foreign policy: an analytical framework. In: GOLDSTEIN, J.; KEOHANE, R. (Ed.). Ideas and foreign policy, beliefs, institutions and political change. Ithaca: Cornell University Press. 1993. p. 102-143.

GUASTINI, R. La "constitucionalización” del ordenamiento jurídico: el caso italiano. In: CARBONELL, M. (Org.). Neocontitucionalismo(s). Madrid: Trotta. 2009. p. 87.

HELLINGER, D. Comparative politics of Latin América: democracy at last? New York: Routledge, 2011.

HERMANN, C. et al. Resolve, accept, or avoid: effects of group conflict on foreign Policy Decisions. International Studies Review, New York, v. 3, n. 2, p. 133-168, 2002. 
HILL, C. The changing politics of foreign policy. London: Palgrave, 2003.

HIRSCHL, R. Towards juristocracy: the origins and consequences of the neoinstitucionalism. Cambridge: Harvard University Press, 2004. HUDSON, V. Foreign policy analises yestarday, today and tomorrow. Mershon International Studies Review, New York, v. 39, p. 216-217, 1995.

HUDSON, V. Foreign Policy analysis: Actor-Specific Theory and the Ground of International Relations. Foreign Policy Analysis, Malden, v. 1, n. 1, p. 1-30, 2005.

INSTITUTO BRASILEIRO DE ANÁLISES SOCIAIS E ECONÔMICAS - IBASE. Relatório de atividades 2014. [2014]. Rio de Janeiro. Disponível em: $<\mathrm{http}: / /$ ibase.br/pt/prestando-contas/relatorios/>. Acesso em: 20 mar. 2015

JACKSON, R.; SORENSEN, G. Introdução às relações internacionais. Rio de Janeiro: Zahar, 2007.

KOSKENNIEMI, M. Carl Schmitt. Hans Morgenthau and the Image of Law in Internacional Relations. In: BYERS, M. The role of law in internacional politics. [s.n.]: Oxford, 2000, p. 17-34.

LAFER, C. A identidade internacional do Brasil e a política externa brasileira: passado, presente e futuro. São Paulo: Perspectiva, 2001. LEÃO, E. S. Tratados Internacionais, Judiciário e Política Externa: uma análise dos julgados da suprema corte brasileira. Espaço Jurídico, Joaçaba, v. 12, n. 2, p. 265-282, jul.-dez. 2011.

LIMA, M. R. S. de. Instituições democráticas e política exterior.

Contexto Internacional, Rio de Janeiro, v. 22, n. 2, p. 265-303, jul.-dez. 2000.

LIMA, M. R. S. de; SANTOS, F. O congresso e a política de comércio exterior. Lua Nova, São Paulo, n. 52, 2001. Disponível em: $<$ http://www.scielo.br/scielo.php?script=sci_arttext \&pid=S010264452001000100006\&lng=en\& nrm=iso >. Acesso em: 20 set. 2012. 
LIMA, M. R. S. de; SANTOS, F. O interesse nacional e a integração regional. Papéis Legislativos, Rio de Janeiro, ano 2, n. 1, abr. 2008. Disponível em: < http://www.plataformademocratica.org/ Publicacoes/22327.pdf >. Acesso em: 24 mar. 2015.

LOPES, D. A Plausibilidade de uma gestão Democrática da Política Externa: algumas hipóteses (insatisfatórias) sobre o caso brasileiro. Cena internacional, [S.l.], v. 10, n. 2, p. 98-118, 2008.

MACIEL, D.; KOERNER, A. Sentidos da Judicializacão da política: duas análises. Lua Nova: Revista de Cultura e Política, São Paulo, n. 57, p. 113-133, 2002.

MAGALHÃES, J. C. A diplomacia pura. Lisboa: Bertrand, 1995 MAQUIAVELO, N. Discursos sobre la primeira década de Tito Lívio. Madrid: Alianza, 1987.

MATTLI, W.; SLAUGHTER, A. M. The role of national courts in the process of european integration: accounting for judicial preferences and constraints. The european court and national courts-doctrine and jurisprudence: legal change and it social context. Oxford: Hart Publishing, 1999. p. 253-277.

MELO, A. L. A Juridicializacão do estado brasileiro: um caminho antidemocrático. Revista Jurídica Consulex, São Paulo, v. 6, n. 125, p. 28-31, mar. 2002.

MERLE, M. La Politique étrangère. Paris: PUF, 1992.

MILNER, H. V.; ROSENDORF B. P. Interests, institutions and information, domestic politics and internacional relations. Princeton: Princeton University Press, 1997.

MINGST, K. Princípios de relações internacionais. Rio de Janeiro: Campus-Elsevier, 2009.

MONTESQUIEU, C. de. O Espírito das leis. Brasília, DF: UNB, 1992. 
PASTOR, R. V.; DALMAU, R. M. Necesidad y oportunidad en el proyecto venezolano de reforma constitucional. Revista Venezolana de Economía y Ciencias Sociales, Caracas, v. 14, n. 2, p. 102-132, 2008. Disponível em: < http://www.scielo.org.ve/pdf/rvecs/v14n2/art07.pdf > Acesso em: 6 abr. 2013.

PASTOR, R. V.; DALMAU, R. M. Presentación. Aspectos generales del nuevo constitucionalismo latinoamericano. In: CORTE CONSTITUCIONAL DE ECUADOR PARA EL PERÍODO DE TRANSICIÓN. EI nuevo constitucionalismo en America Latina. Quito: Corte Constitucional del Ecuador, 2010a. p. 9

PASTOR, R. V.; DALMAU, R. M.¿Se puede hablar de un nuevo constitucionalismo latinoamericano? In: CONGRESSO MUNDIAL DA ASSOCIAÇÃO INTERNACIONAL DE DIREITO CONSTITUCIONAL, 8, Cidade do México. Dezembro, 2010. Anais eletrônicos... Cidade do México, 2010b. Disponível em: <http://www. juridicas.unam.mx/wccl/ponencias/13/245.pdf> . Acesso em: 30 set. 2011.

PASTOR, R. V.; DALMAU, R. M. 2011. El nuevo constitucionalismo latinoamericano: Fundamentos para uma construcción doctrinal. Revista General de Derecho Público Comparado, n. 9, Valencia. Disponível em: $<$ http://dialnet.unirioja.es/servlet/articulo?codigo=3690557>. Acesso em: 10 maio 2013

POLVEIRO JUNIOR, E. E. Relações Internacionais na Constituição de 1988 e suas Consequências na Política Externa Brasileira. In: BRASIL. Congresso Nacional. Senado Federal. Constituição de 1988: o Brasil 20 anos depois. Os alicerces da redemocratização, 2008. v. 1. Disponível em: <http://www12.senado.gov.br/publicacoes/estudos-legislativos/tiposde-estudos/outras-publicacoes/volume-i-constituicao-de-1988/relacoesinternacionais-as-relacoes-internacionais-na-constituicao-de-1988-e-suasconsequencias-na-politica-externa-brasileira>. Acesso em: 15 mar. 2015.

REUS-SMIT, S. The politics of internacional law. Cambridge:

Cambridge Univesity Press, 2004. 
SANTORO, M. Democracia e Política Externa no Brasil. Revista de Estudos Políticos, [S.l.], n. 4, 2012. Disponível em: <http://www. plataformademocratica.org/Publicacoes/21641_Cached.pdf $>$. Acesso em: 19 abr. 2015.

SNYDER, R.; BRUCK, H. W.; SAPIN, B. Foreign policy decision making: an approach to the study of International Politics. New York: Free Press, 1962.

SNYDER, R.; BRUCK, H. W.; SAPIN, B. Decision-Making as an approach to the study of internacional politics. In: SNYDER, R.; BRUCK, H. W.; SAPIN, B. Foreign policy decision making. London: Palgrave Macmillan, 2002. p. 1-20.

STOLLEIS, M. Stato e ragione di stato nella prima età moderna. Bologna: Il Mulino, 1998.

TAVARES, C.; FREITAS, R. Constitucionalismo e Democracia na América Latina. In: FREITAS, R.; MORAES, G. Unasul e o novo costitucionalismo Latino-Americano. Curitiba, EdCRV, 2013. p. 29.

WHITE, B.; CLARKE, M. Understanding foreign policy: the foreign policy systems approach. Aldershot: Edward Elgar, 1989.

WOLKMER, A. C.; AUGUSTIN, S.; WOLKMER, M. de F. O Novo Direito a Água no Constitucionalismo da América Latina. Revista Internacional Interdisciplinar Interthesis, Florianópolis, v. 9, n. 1, p. 51-69, jan.-jul. 2012.

Sergio Urquhart Cademartori é graduado em Direito pela Universidade Federal de Santa Maria (1976), mestre em Direito pela Universidade Federal de Santa Catarina (1990); doutor em Direito pela Universidade Federal de Santa Catarina (1997); e pós-doutor pela Unisinos (RS). Atualmente é professor visitante do doutorado da Universidade de Granada e da Universidade Técnica de Lisboa, professor permanente do Centro Universitário La Salle-Canoas, Consultor ad hoc da CAPES. Tem experiência na área de Filosofia, com ênfase em Epistemologia, 
atuando principalmente nos seguintes temas: democracia, garantismo, direitos fundamentais, constituição e administração pública. Professor vinculado ao projeto de mestrado em Direito e Sociedade da Unilasalle.

E-mail: scademartori@uol.com.br

Endereço profissional: Unilasalle Canoas, Av. Victor Barreto, n. 2.288, Canoas, RS. CEP: 92010-000.

José Alberto Antunes de Miranda é graduado em Direito pela Universidade do Vale do Rio dos Sinos - Unisinos (1996), especialista em Integração e Mercosul pela UFRGS (1999), mestre em Relações Internacionais pela UFRGS (2004), e doutor em Estudos Estratégicos Internacionais pela Universidade Federal do Rio Grande do Sul - UFRGS (2012). Atualmente é Assessor de Assuntos Interinstitucionais e Internacionais, professor permanente e Pesquisador do Programa de Pós-graduação em Direito e Sociedade, professor do curso de Relações Internacionais do Centro Universitário La Salle - Unilasalle, membro da Comissão de Internacionalização do Conselho de Reitores das Universidades Brasileiras - CRUB.

E-mail: antunes@unislaalle.edu.br

Endereço profissional: Unilasalle Canoas, Av. Victor Barreto, n. 2.288, Canoas, RS. CEP: 92010-000. 